\title{
Thyroid Gland Follicular Carcinoma, Encapsulated Angioinvasive
}

National Cancer Institute

\section{Source}

National Cancer Institute. Thyroid Gland Follicular Carcinoma, Encapsulated

Angioinvasive. NCl Thesaurus. Code C156122.

An encapsulated follicular carcinoma of the thyroid gland which shows angioinvasion. 